\title{
Imagens arquetípicas na Gestão de Pessoas
}

\begin{abstract}
RESUMO
Entender como as pessoas se relacionam e o que as motivam é um grande diferencial em qualquer organização do conhecimento. Jung estudou a mente humana e a relação do consciente e subconsciente, tendo formulado a teoria dos arquétipos. A partir desses estudos sobre a personalidade do ser humano, outros pesquisadores sentiram a necessidade de criar imagens arquetípicas que representassem e exaltassem as características predominantes dos tipos psicológicos humanos (MARK; PEARSON, 2001) e organizacionais (HANDY, 1994). Este artigo tem o objetivo de esclarecer sobre os perfis arquetípicos humanos e organizacionais através de uma pesquisa quantitativa com estudantes de pós-graduação (mestrado/doutorado). Tal estudo foi desenvolvido durante a disciplina de Desenvolvimento Humano na Universidade Federal de Santa Catarina (UFSC) e foram aplicados questionários para identificar o perfil dos 24 estudantes participantes, suas imagens arquetípicas individuais e seus graus de satisfação com a função que ocupam atualmente na organização a qual pertencem. Nos resultados percebe-se que os sujeitos apresentam todas as imagens arquetípicas com destaque para o Explorador e Criador. Almejam a empresa Atena em que o indivíduo seja valorizado dentro da equipe de trabalho e tenha a recompensa dividida, no entanto, percebem suas empresas no perfil Apolo ligado a regras, normas e procedimentos lógicos. Ao se compreender isso, as organizações podem utilizar das imagens arquetípicas na gestão de pessoas para motivar os colaboradores.
\end{abstract}

Palavras-chave: Arquétipos. Imagens Arquetípicas. Gestão de pessoas.

Jaqueline de Souza Tartari jaquelinetartari@gmail.com Mestranda em Engenharia em Gestão do Conhecimento Universidade Federal de Santa Catarina - Brasil

Wescley José Lira wj.consultoria@hotmail.com Mestrando em Engenharia em Gestão do Conhecimento Universidade Federal de Santa Catarina - Brasil 


\section{INTRODUÇÃO}

Mudanças sociais ocorrem naturalmente com a evolução humana e alguns norteadores podem ser explicados pela busca do homem por melhor qualidade de vida e a necessidade cada vez mais crescente de suprir as vontades individuais e coletivas. A sociedade se transforma desde sua existência e as organizações precisam se adaptar a novos contextos, inovando para conquistar espaço em mercados existentes e futuros e investindo principalmente em capital humano, que é reconhecidamente o principal ativo para gerar conhecimento evidenciado na literatura.

Asorganizações começaram a entenderque o conhecimentoéo recurso corporativo de maiorvalor na sociedade contemporânea e que ele precisa ser compartilhado para que possa ser reutilizado e gerar, consequentemente, novos conhecimentos e isso só é possível por causa das pessoas envolvidas. Sem o compartilhamento do conhecimento, o aprendizado é limitado a um nível individual. Para poder compreender o conhecimento, o sujeito e as organizações algumas teorias e avaliações surgiram para dar conta do padrão complexo que a sociedade pósmoderna apresenta. Uma delas está baseada nas teorias da psicologia complexa de Jung.

Jung estudou a mente humana e identificou uma gama de fatores que partem do consciente e subconsciente e influenciam nas atitudes. Seus estudos são essenciais para que estudiosos consigam construir imagens arquetípicas dos indivíduos e das organizações de modo a traçar algumas representações de personalidade. Dessa maneira, se pode compreender melhor o sujeito e a estruturação das organizações humanas em uma relação de trabalho-tarefa-ambiente que sejam mais adequados para a realização e bem estar social.

Diante do exposto, o presente artigo trouxe na introdução uma visão geral das transformações pelas quais a sociedade vem passando e a necessidade de valorizar o capital humano nesse contexto. Na segunda seção, faz-se uma discussão que evidencia as pessoas como elemento central das organizações, pois, uma gestão inequívoca dos indivíduos prejudica o todo. Na sequência, tem-se uma explanação sucinta a respeito dos estudos de tipos psicológicos desenvolvidos por Jung seguido, na seção quatro, de uma análise da visão individual e coletiva abordada por autores que construíram imagens arquetípicas para melhor compreensão desses fenômenos de personalidade. Com base na discussão e teorias abordadas até então, a seção cinco irá apresentar os procedimentos metodológicos e a seis tratará de analisar os testes de personalidade aplicados com estudantes de pós-graduação (mestrado e doutorado) a fim de verificar quais são suas imagens arquetípicas e quais são os seus deuses da organização em que estão vinculados. Assim, para encerrar o artigo, apresentam-se as considerações finais e referências que alicerçaram a pesquisa.

\section{GESTÃO DE PESSOAS (ORGANIZAÇÕES HUMANAS)}

Gerir no mundo atual é poder entender e conceituar habilidades, ações, inteligência, normas e principalmente o comportamento humano, e por este motivo o enfoque do trabalho se dá na gestão de pessoas em organizações humanas e no desenvolvimento humano. A tarefa de administrar, gerenciar ou gerir nas organizações empresariais dos dias atuais e como dar enfoque no desenvolvimento humano dessas organizações é uma tarefa que irá direcionar este trabalho.

Conforme Paladini (2008) gestão é a arte (habilidade, aptidão, competência) de tomar decisões. É a forma de como se alcançar os resultados pretendidos ou ainda é a administração do seu dia a dia. Gerir significa, portanto, conduzir outras pessoas ou direcioná-las a fazer o que se deseja. Dirigir implica na orientação e condução do trabalho de outras pessoas e para que isso aconteça devem-se organizar as tarefas para que o fim seja atingido. Para se conseguir o que se deseja por meio de outrem é necessário motivá-lo. Não é fácil motivar alguém, portanto é necessário conhecer o colaborador, saber o que ele deseja e o que não deseja e quais seus objetivos pessoais e profissionais.

Quando se relaciona a gestão com o termo "pessoas" novos conhecimentos são incorporados de outras áreas além da administração como a psicologia, antropologia, biologia, entre outras. Assim, segundo discorre Fischer (2001) trata-se de um conjunto organizado de políticas, práticas e processos característicos das organizações. O gestor nesse processo de gestão irá gerir pessoas, sejam elas colaboradores, funcionários, amigos ou pessoal de apoio.

Para lidar com pessoas no cotidiano é necessário ter técnicas da administração e demais disciplinas complementares, ainda que seja de forma simplificada e não como expert em cada uma delas, uma vez que é uma arte entender, compreender e conviver com seus pares. Nesse sentido é preciso entender as pessoas, entender o ambiente e a mudança, uma vez que, o mundo contemporâneo muda constantemente e numa velocidade imensurável a qual não se consegue acompanhar em virtude do advento da cultura digital.

Os sistemas tradicionais de gestão eram inspirados em Ford e Taylor que se baseavam no controle das pessoas que por sua vez eram passivas, já que eram controladas. Atualmente, a organização ao se desenvolver, 
desenvolve pessoas, e estas, ao se desenvolverem, desenvolvem a organização, há uma troca de interesses entre os atores do processo, tanto organização quanto colaborador. A pessoa é a gestora da sua relação com a instituição, bem como do seu desenvolvimento pessoal e com as mudanças decorrentes da sociedade do conhecimento se requer que essa troca seja realizada com confiança e valorização.

\subsection{Foco no desenvolvimento humano}

Gerir pessoas é uma tarefa árdua e que requer conhecimentos multidisciplinares e interdisciplinares nas organizações humanas. Portanto, há a necessidade de se analisar o Desenvolvimento Humano como parte intrinsicamente ligada ao processo de gestão de pessoas. O Desenvolvimento Humano é uma ciência que merece ser estudada separadamente e em vários contextos afirma Dessen e Costa Júnior (2008).

A Ciência do Desenvolvimento delineia um conjunto de estudos interdisciplinares que se dedicam a entender os fenômenos relacionados ao desenvolvimento dos indivíduos, englobando as áreas social, psicológica e biocomportamental, focalizando a ontogênese dos processos evolutivos desde seus eventos genéticos constitutivos até os processos culturais (DESSEN; COSTA JÚNIOR, 2008).

É possível estabelecer entre as organizações na gestão de pessoas interfaces com algumas imagens arquetípicas, ou ainda identificar quais delas estão presentes nas organizações com foco no desenvolvimento humano partindo do princípio da empatia. Acredita-se que através da gestão de pessoas e imagens arquetípicas é possível proporcionar às pessoas experiências prazerosas oferecendo funções dentro da organização que vão ao encontro dos perfis de personalidade dos indivíduos.

\section{ARQUÉTIPOS}

Os arquétipos são muito utilizados na literatura atual para explicar as mudanças profissionais nas organizações (BROCK, 2006) e buscam na psicologia respaldo para entender a evolução e mudanças nas formas de gerir pessoas dentro e fora da organização. Dessa forma, arquétipos podem ser considerados, para fins desse artigo, um padrão identificado nas atitudes que pode ser aplicado de forma individual e coletiva.

Na obra de Mark e Pearson (2001, p. 18) aparecem algumas definições de renomados autores sobre o que é um arquétipo:

Formas ou imagens de natureza coletiva, que ocorrem em praticamente toda a terra como componentes de mitos e, ao mesmo tempo, como produtos individuais de origem inconsciente. (C. G. Jung, Psychology and Religion).

Jung [...] estudou o que nós sentimos e o que fantasiamos quando estamos fazendo algo. Ou seja, os arquétipos não são apenas ideias elementares, mas também, e igualmente, sentimentos elementares, fantasias elementares, visões elementares. (Marie-Louise Von Franz, Psyche and Matter).

Os arquétipos são inúmeros, incontáveis, porém, Jung nomeia alguns que estão em permanente contato com o eu. São eles: a persona, a sombra, a anima, o animus e o self - este também é denominado de si mesmo e constitui o núcleo central não só do inconsciente, mas, também, de toda a psique (RAMOS, 2002).

\subsection{O Inconsciente e os Arquétipos}

Os arquétipos representam a expressão de toda a existência humana. São sistemas vivos de reação e disposição que por meios invisíveis e, portanto, mais eficazes, determinam a vida individual (JUNG, 2004). Para Jung os arquétipos se manifestam no inconsciente coletivo e o que se percebe e foi definido neste trabalho são as imagens arquetípicas que já se encontram em um nível tangível e, assim, consciente.

O inconsciente não é somente um a priori histórico gigantesco, em vez disso a fonte dos instintos, na medida em que os arquétipos não são mais as formas em que se manifestam os instintos. Contudo, a fonte da vida que é o instinto da vida emana também todo do criativo, de tal maneira que o inconsciente não é somente condicionalmente histórico, mas ao mesmo tempo engendra o impulso criativo: igual a natureza, que, sendo terrivelmente conservadora, contudo supera seu próprio condicionamento histórico graças aos seus atos criativos. (JUNG, 2004, p. 159). 
O autor também cita quando discorre sobre os arquétipos e o inconsciente a respeito da função transcendente. Percebe-se que a função transcendente é vital na gestão de pessoas:

O ser humano está pouco capacitado em aceitar os argumentos do outro, apesar de ser essa a capacidade básica indispensável de toda comunidade humana. Com essa dificuldade geral há de contar todo aquele que se disponha a estabelecer uma relação consigo mesmo. Na mesma medida em que não se aceita o outro, tampouco será concedido o direito a existência do outro que há dentro de si mesmo, e vice-versa. A capacidade de diálogo interior é uma escala para se medir a objetividade exterior. (JUNG, 2004, p. 92).

Na continuação do pensamento de Jung o próximo capítulo irá discorrer sobre o individuo e o coletivo.

\section{O INDIVÍDUO E O COLETIVO}

Jung identificou diferentes atitudes e funções, ou seja, a psique age e reage em determinada direção. Contudo, através principalmente da observação de seus pacientes, ele especificou as características correspondente a determinado perfil de uma espécie ou de uma generalidade, isto é, características que podem ser aplicadas por atitudes gerais que se manifestam em muitas formas individuais (MAROCHI, 2003).

Partindo da identificação de características predominantes nas atitudes, Jung dividiu em sujeitos extrovertidos e em sujeitos introvertidos e adicionou as variáveis pensamento, sentimento, intuição e sensação. A essas variáveis foi possível acrescentar o julgamento e a percepção, sendo o julgamento fruto do raciocínio lógico que une sensação e pensamento; e a percepção surge por motivos não racionais como a intuição e o sentimento. O cruzamento dessas diferentes características podem dizer muito sobre a personalidade de um indivíduo ou coletivo, pois, parte não só de uma análise superficial de suas ações, como também tenta investigar quais motivos e sentimentos estão subjacentes a determinadas ações e vontades de agir (Quadro 1).

Quadro 1 - Resumo das Características identificadas nos estudos de Jung

\begin{tabular}{|c|c|}
\hline $\begin{array}{l}\text { Extroversão }(E) \\
\text { Pessoas que preferem a Extroversão tendem } \\
\text { a priorizar o mundo das pessoas e coisas }\end{array}$ & $\begin{array}{c}\text { Introversão }(I) \\
\text { Pessoas que preferem a Introversão tendem a } \\
\text { priorizar o mundo interno das ideias e impressões }\end{array}$ \\
\hline $\begin{array}{c}\text { Sensação (S) } \\
\text { Pessoas que preferem a Sensação tendem a } \\
\text { priorizar o presente e as informações concretas } \\
\text { obtidas pelos seus sentidos }\end{array}$ & $\begin{array}{c}\text { Intuição }(N) \\
\text { Pessoas que preferem a Intuição tendem } \\
\text { a priorizar o futuro, com uma visão para modos } \\
\text { e possibilidades }\end{array}$ \\
\hline $\begin{array}{c}\text { Pensamento }(T) \\
\text { Pessoas que preferem o Pensamento tendem } \\
\text { a basear suas decisões em análises lógicas e } \\
\text { objetivas de causas e efeitos }\end{array}$ & $\begin{array}{c}\text { Sentimento }(F) \\
\text { Pessoas que preferem o Sentimento tendem } \\
\text { a basear suas decisões primeiramente em } \\
\text { valores e em seguida em seus interesses } \\
\text { e preocupações pessoais }\end{array}$ \\
\hline $\begin{array}{c}\text { Julgamento }(\mathrm{J}) \\
\text { Pessoas que preferem o Julgamento tendem } \\
\text { a planejar e organizar suas vidas e preferem coisas } \\
\text { estabelecidas }\end{array}$ & $\begin{array}{c}\text { Percepção }(P) \\
\text { Pessoas que preferem Percepção tendem a ser mais } \\
\text { flexíveis e espontâneas na sua vida e preferem manter } \\
\text { as opções mais abertas }\end{array}$ \\
\hline
\end{tabular}

Fonte: Marochi (2003, p. 139).

Os estudos de Jung serviram de base teórica sólida para muitos outros pesquisadores que foram complementando e contextualizando a sua ciência a estudos de casos específicos e devidas aplicações para atestar a veracidade dos dados, como, por exemplo, Briggs e Myers (1987) que utilizaram as ideias desenvolvidas por Jung juntamente com outras teorias para identificar as preferências e os perfis das pessoas nas organizações e na educação. No presente trabalho, vamos apresentar as doze (12) imagens arquetípicas utilizadas por Mark e Pearson (2001) para identificar a personificação do indivíduo e da organização de acordo com símbolos intrínsecos na nossa cultura e trazer à tona os estudos de Handy (1994) que fazem uma analogia das organizações com quatro deuses da mitologia. 


\subsection{Imagens arquetípicas individuais}

Mark e Pearson (2001) trabalharam há mais de 30 anos com pesquisa e gestão de pessoas e aplicaram, ao longo de suas trajetórias, as ideias desenvolvidas por Jung. Assim, elas começaram a trabalhar em conjunto e desenvolveram imagens arquetípicas que pudessem auxiliar no trabalho de gestão de pessoas e marketing, agregando às suas práticas estudos na área da psicologia e psicanálise para entenderem melhor seus clientes internos (colaboradores) e externos. Entre as imagens arquetípicas identificadas por elas, as que tinham maiores ocorrências e frequências são as doze (12) listadas a seguir, cada uma com sua breve descrição (quadro 2).

Quadro 2 - Imagens Arquetípicas e suas funções básicas na vida das pessoas

\begin{tabular}{|c|c|}
\hline Arquétipo & Ajuda as pessoas a \\
\hline Criador & Criar algo novo \\
\hline Prestativo & Ajudar os outros \\
\hline Governante & Exercer o controle \\
\hline Bobo da Corte & Se divertirem \\
\hline Cara Comum & Estarem bem assim como são \\
\hline Amante & Encontrar e dar amor \\
\hline Herói & Agir corajosamente \\
\hline Fora-da-lei & Quebrar regras \\
\hline Mago & Influir na transformação \\
\hline Inocente & Manter ou renovar a fé \\
\hline Explorador & Manter a independência \\
\hline Sábio & Compreender o mundo em que vivem \\
\hline
\end{tabular}

Segundo as autoras, cada indivíduo possui uma dessas imagens arquetípicas em evidência, mas dependendo do contexto podem manifestar temporariamente outra. Isso ocorre por causa da necessidade do ser humano de defesa e de se adequar a determinadas situações.

\subsection{Imagens arquetípicas nas organizações}

Handy (1994) faz a analogia de arquétipos nas organizações ao representar a figura de deuses da mitologia e a relação com a cultura (Quadro 3). Cada Deus é específico para uma cultura e o conjunto de atividades, momentos e situações vivenciados pela organização. Por isso não existe um deus mais correto ou melhor que outro, o contexto é quem define o deus atual e mudança cultural necessária e estratégica (HANDY, 1994). A seguir segue a explicação de cada deus e sua respectiva manifestação na organização a partir de Handy (1994):

- Cultura de clube, representada por Zeus: tradição patriarcal, poder irracional e benevolência de pai. A cultura de clube é encontrada em pequenas organizações empreendedoras e familiares;

- Cultura de Função, representada por Apolo e o templo: guerreiro. Protetor das regras e culto destinado à beleza e perfeição. As funções e tarefas de uma organização precisam ser cumpridas, independente das pessoas que a compõe, seguindo normas e procedimentos lógicos. Muito adotada em organizações que não queriam mudar e não incentivam a criatividade;

- Cultura de tarefa, representada pela Deusa Atena e a rede: valorização do indivíduo dentro da equipe de trabalho e recompensa dividida. Ideal para organizações que solucionam problemas (prestação de serviços);

- Cultura da existência, representada pelo Deus Dionísio e estrelas agrupadas: são comunidades que se reúnem para atingir objetivos pessoais, como exemplo as Universidades, consultores.

A partir de agora será apresentada a pesquisa realizada com os alunos de pós-graduação (mestrado/ doutorado) de três diferentes instituições superiores para se compreender na prática como podem ser verificadas as imagens arquetípicas individuais e coletivas, assim como, o perfil das organizações em que os estudantes estão vinculados. 


\section{PROCEDIMENTOS METODOLÓGICOS}

Com base em seus objetivos, de acordo com Gil (2002), esta é uma pesquisa descritiva que estudou determinadas características relacionadas às imagens arquetípicas dos alunos e das respectivas empresas em que estão vinculados. Caracterizou-se como quantitativa a partir da aplicação de dois questionários que apresentam escores para definir as imagens arquetípicas. A pesquisa quantitativa prevê a mensuração de variáveis já estabelecidas e procura explicar suas influências sobre outras variáveis, conta com análise de frequência de incidência e métodos estatísticos (CHIZZOTTI, 2006). A amostra foi do tipo não probabilística e intencional composta por vinte e quatro (24) alunos do mestrado/doutorado de diferentes áreas e universidades.

O primeiro teste chamado de índice de mitos heroicos foi desenvolvido por Carol S. Pearson, Sharon V. Seivert, Mary Leonard e Hugh Marr. As pessoas nesse teste recebem um escore numérico indicando o seu grau de identificação com os doze arquétipos descritos no livro de Pearson já explicado neste trabalho. Todos os doze arquétipos são importantes e cada um deles traz consigo uma dádiva especial. Nenhum é melhor nem pior do que o outro. Assim, não existem respostas certas ou erradas.

O segundo teste aplicado é chamado de questionário deuses da organização e obtém a imagem arquetípica da empresa na visão do sujeito e em um segundo momento obtém a imagem arquetípica de acordo com a importância de cada item na opinião pessoal do sujeito. As pessoas nesse segundo teste indicam um escore numérico ordenado de acordo com seu grau de identificação com os quatro arquétipos organizacionais.

De acordo com Severino (2007) o questionário corresponde a um conjunto de questões, sistematicamente articuladas com o intuito de levantar informações escritas por parte dos sujeitos da pesquisa para que sejam conhecidas suas opiniões. Foi formado por questões fechadas. Os questionários foram enviados por e-mail para os alunos da Unidade de Desenvolvimento Humano e Gestão além de outros alunos que foram indicados e que estavam matriculados em um programa de mestrado ou doutorado independentemente da área, programa ou universidade.

\section{APRESENTAÇÃO E DISCUSSÃO DOS RESULTADOS}

Neste capítulo serão apresentados os resultados e discussões dos dados obtidos neste estudo. Foram analisados os dados referentes aos questionários onde o objetivo geral é verificar as imagens arquetípicas pessoais e organizacionais em estudantes de pós-graduação em nível de mestrado e doutorado.

A amostra foi composta por vinte e quatro (24) estudantes de ambos os sexos com 10 indivíduos do sexo masculino e 14 do sexo feminino (Gráfico 1) e 54\% deles tem até 30 anos (Gráfico 2).

Gráfico 1 - Perfil por sexo

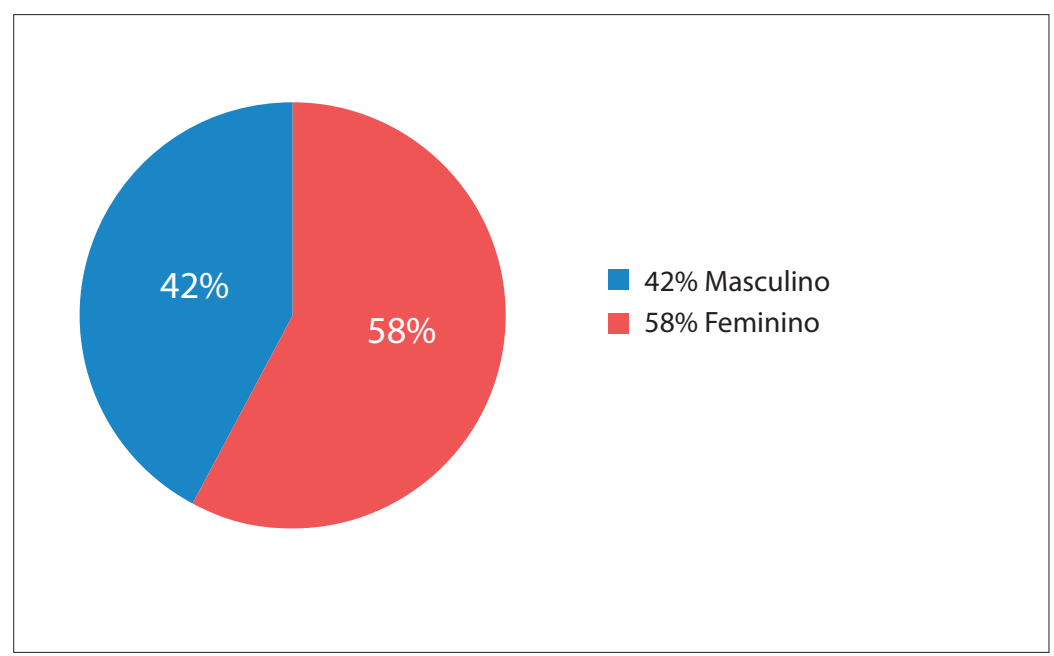

Fonte: desenvolvido pelos autores (2015). 
Gráfico 2 - Perfil por faixa etária

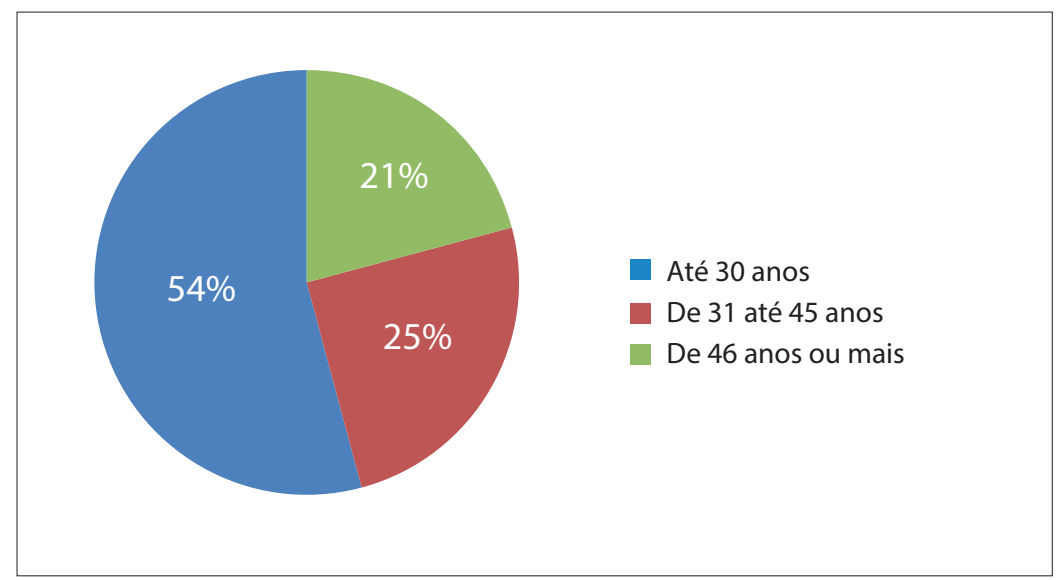

Fonte: desenvolvido pelos autores (2015).

A maior parte da amostra está cursando o doutorado (Gráfico 3). Os participantes da pesquisa são da Universidade Federal de Santa Catarina (UFSC), Universidade do Estado de Santa Catarina (UDESC) e um deles é da University of St Andrews (Escócia).

Gráfico 3 - Nível de pós-graduação que cursa

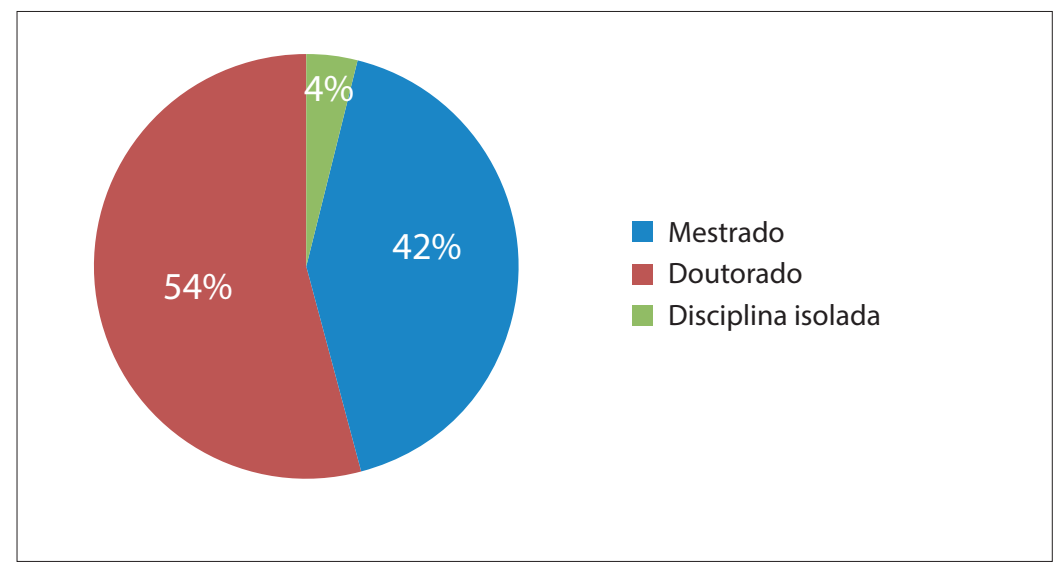

Fonte: desenvolvido pelos autores (2015).

Os participantes da pesquisa apresentam a graduação em sua maior parte na área das ciências sociais aplicadas e a sua pós-graduação em nível de mestrado e doutorado na área das Engenharias (Gráfico 4). No entanto, vale lembrar que o Curso de Pós-graduação em Engenharia e Gestão do Conhecimento (PPG/EGC), o qual se encontra uma parcela dos estudantes, apresenta três linhas de pesquisa: Engenharia, Gestão e Mídia, sendo que essa última se aproxima mais da área das ciências sociais aplicadas apesar de ter sido considerada na área de Engenharias (Gráfico 5). 
Gráfico 4 - Área da graduação

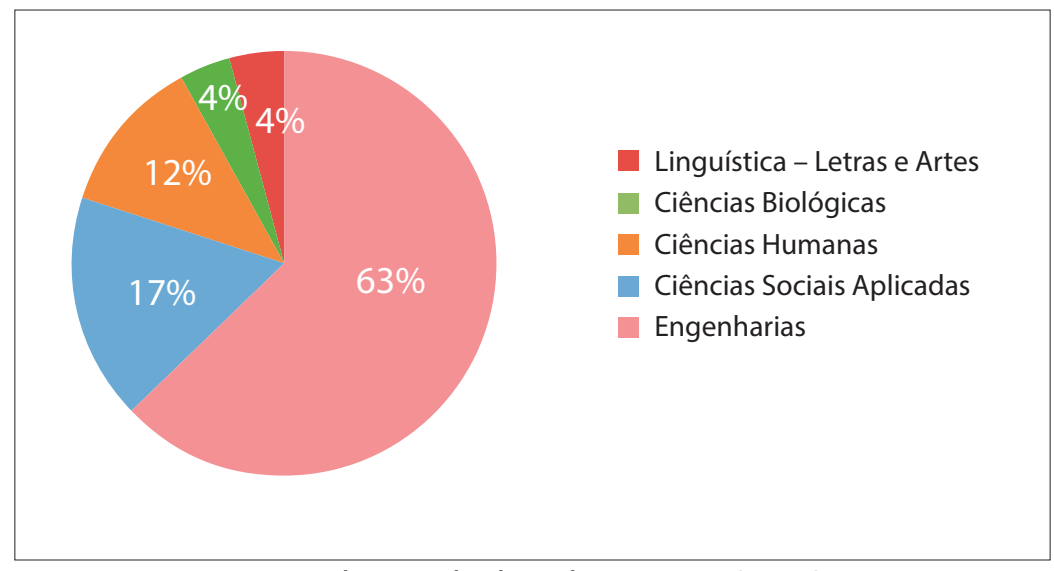

Fonte: desenvolvido pelos autores (2015).

Gráfico 5 - Área da pós-graduação

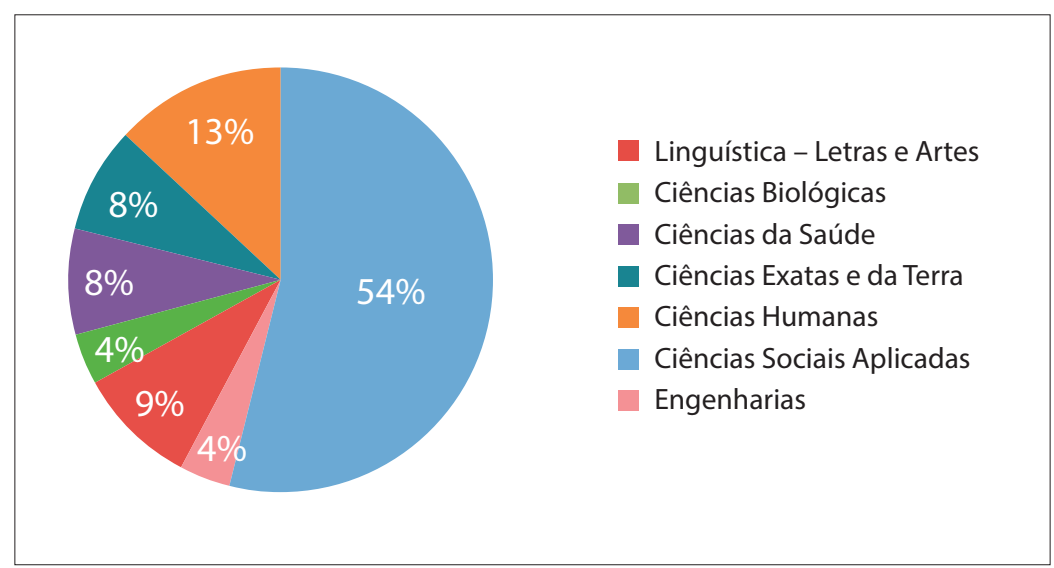

Fonte: desenvolvido pelos autores (2015).

Os arquétipos de cada um deles foram avaliados individualmente e posteriormente lançados de maneira coletiva e desse modo foi possível traçar a imagem arquetípica desse grupo participante a partir da média (Gráfico 6). Pode se observar que o arquétipo do Explorador seguido pelo do Criador foram os que obtiveram os índices mais altos em uma escala de pontuação que ia do número 6 até o 30. Os que obtiveram a menor pontuação foram os arquétipos do Órfão e do Destruidor. Fica claro com o gráfico abaixo que todas as imagens arquetípicas estão presentes em todos os estudantes e surge um indicativo de que o perfil dos pós-graduandos seja de independência e ligado a criatividade e inovação. 
Gráfico 6 - Imagem arquetipica do grupo participante

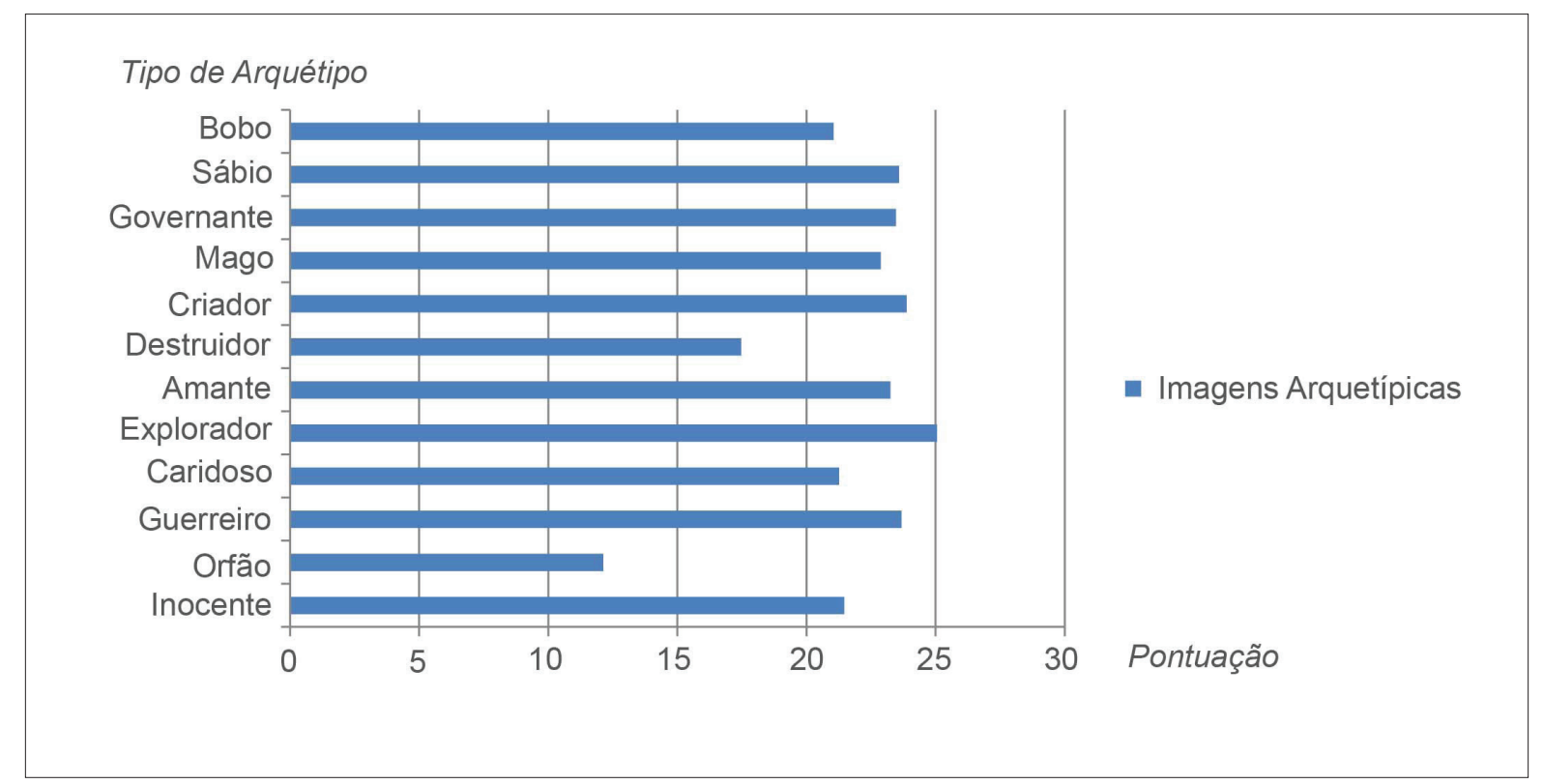

Fonte: desenvolvido pelos autores (2015).

Para compreender melhor as imagens arquetípicas organizacionais é necessário compreender em quais empresas os estudantes estão vinculados. A maior parte deles está vinculada a Universidade como estudante bolsista ou professor; a escritórios e agências de design, publicidade ou arquitetura; ou a área da Educação (Gráfico 7).

Gráfico 7 - Tipo de empresa que os estudantes estão vinculados

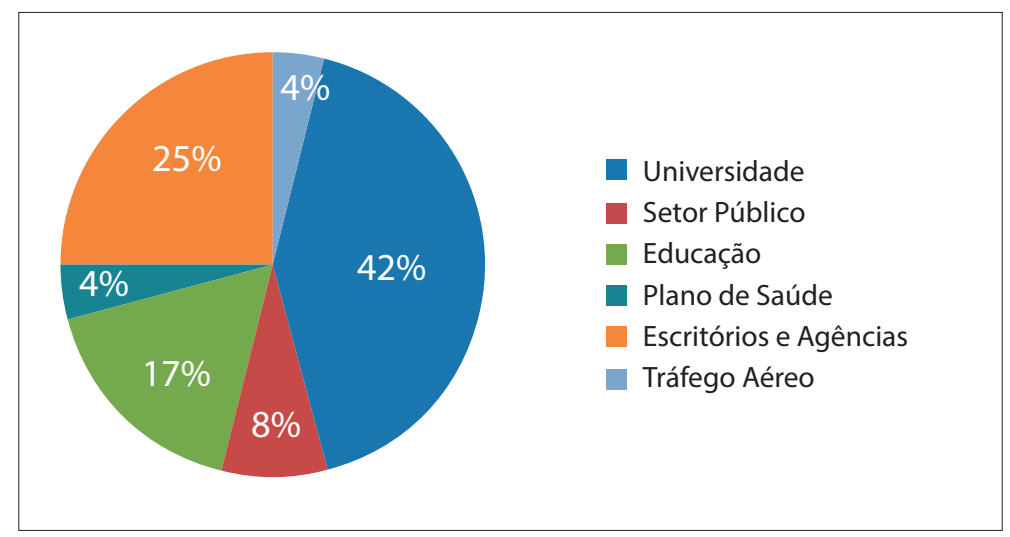

Fonte: desenvolvido pelos autores (2015).

Quanto às imagens arquetípicas organizacionais foi possível observar que a maioria deles considera que a sua empresa apresenta uma maneira mais tradicional ligada a regras, normas e procedimentos lógicos que remonta o arquétipo de Apolo. Contudo, a maior parte almeja uma empresa Atena em que o indivíduo seja valorizado dentro da equipe de trabalho e tenha a recompensa dividida (Gráfico 8). 
Gráfico 8 - Imagens arquetípicas organizacionais

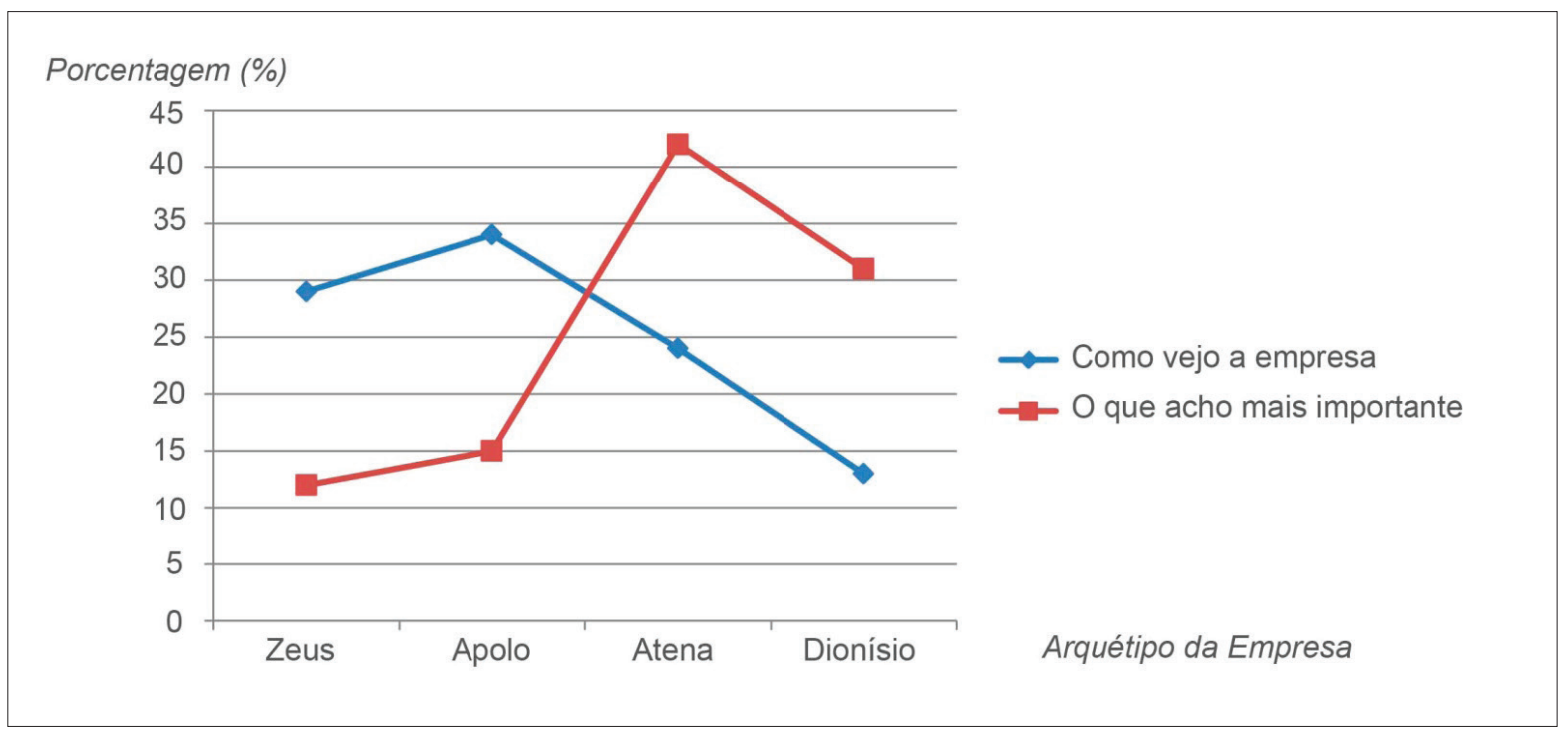

Fonte: desenvolvido pelos autores (2015).

\section{CONSIDERAÇÕES FINAIS}

O objetivo desta pesquisa foi verificar as imagens arquetípicas pessoais e organizacionais em estudantes de pós-graduação em nível de mestrado e doutorado. No grupo pesquisado percebeu-se que todas as imagens arquetípicas estão presentes em todos os estudantes. No entanto, o arquétipo do Explorador seguido pelo do Criador foram os que obtiveram os índices mais altos na escala de pontuação e os arquétipos do Órfão e do Destruidor obtiveram a menor pontuação. Isso pode ter ocorrido pelo perfil do grupo estar ligado à área da Educação, escritórios de Design, Publicidade ou Arquitetura, daí surge um indicativo de independência ligado à criatividade e inovação.

Apesar do perfil criativo e inovador dos estudantes foi possível observar que a maioria deles considera que a sua empresa está ligada a regras, normas e procedimentos lógicos que remonta o arquétipo de Apolo. Assim, a maior parte almeja uma empresa Atena em que o indivíduo seja valorizado dentro da equipe de trabalho e tenha a recompensa dividida.

Avaliar as imagens arquetípicas e sua relação com os deuses das organizações pode ser um instrumento valioso. O nível tangível em que os sujeitos dessa pesquisa indicam manifestar seus instintos e desejos sugere uma disparidade com a empresa e trabalho ao qual estão vinculados. Isso remete a história destas pessoas e empresas, além dos seus potenciais criativos. À medida que gestão de pessoas implica em conduzir as pessoas ou direcioná-las a fazer o que se deseja é necessário considerar quem são estes sujeitos e que local é este de trabalho. Deste modo, a motivação pode surgir a partir do momento em que esse ambiente é percebido e modificado em prol do colaborador.

Ao se entender os arquétipos permite-se conhecer as possíveis configurações do inconsciente coletivo e desta forma se autocompreender melhor como ser vivo-criativo. Isso posto, podem-se estabelecer estratégias internas e externas na busca da transcendência para poder então lidar com o outro numa ação de trabalhar consigo mesmo. Em decorrência disso se empoderam os processos de comunicação e gestão de pessoas. Conclui-se então que as imagens arquetípicas são valiosas na identificação do perfil do sujeito, da sua relação com o coletivo e na definição do perfil da organização. 


\title{
ARCHETYPAL IMAGES IN PEOPLE MANAGEMENT
}

\begin{abstract}
Understanding how people relate and what motivates them is a big difference in any organization of knowledge. Jung studied the human mind and the relationship between the conscious and subconscious, having formulated the theory of archetypes. From these studies on the human personality, other researchers felt the need to create archetypal images that represent and appraise the predominant features of human psychological types (Mark and Person) and organizational (Handy). This article aims to clarify the archetypal human and organizational profiles through a quantitative research with post graduate students (Masters / $\mathrm{PhD}$ ). This study was conducted during the Human Development course at the Federal University of Santa Catarina (UFSC) and questionnaires were used to identify the profile of the 24 students participants to identify their individual archetypal images and their levels of satisfaction with the position they currently occupy in the organization which they belong to. The results showed that the subjects have all the archetypal images with emphasis on the Explorer and Creator. They aim at having an Athena company where the individuals are valued within the team they work and the rewards are shared. However, they perceive their companies according to the Apollo profile with rules, standards and logical procedures. By understanding these issues, organizations can use the archetypal images in people management to motivate employees.
\end{abstract}

Keywords: Archetypes. Archetypal images. People management.

\section{REFERÊNCIAS}

BRIGGS, K.; MYERS, I. B. Myers-Briggs Type Indicator Form G. Palo Alto, CA: Consulting Psychologist Press, 1987.

BROCK, David M. The changing professional organization: A review of competing archetypes. International Journal of Management Reviews, Manchester, v. 8, n. 3, p. 157-174, 2006.

CHIZZOTTI, Antonio. Pesquisa em ciências humanas e sociais. 8. ed. São Paulo: Cortez, 2006.

DESSEN, Maria Auxiliadora; COSTA JÚNIOR, Áderson Luiz. A ciência do desenvolvimento humano: tendências atuais e perspectivas futuras. Porto Alegre: Artmed, 2008.

FISCHER, André Luiz. O conceito de modelo de gestão de pessoas: modismo e realidade em gestão de recursos humanos nas empresas brasileiras. In: DUTRA, Joel Souza et al (Org.). Gestão por competências: um modelo avançado para o gerenciamento de pessoas. São Paulo: Gente, 2001. p. 9-23.

GIL, Antonio Carlos. Como elaborar projetos de pesquisa. 4. ed. São Paulo: Atlas, 2002.

HANDY, Charles. Deuses da administração: como enfrentar as constantes mudanças da cultura empresarial. São Paulo: Saraiva, 1994.

JUNG, Carl Gustav. La dinámica de lo inconsciente. Espanha:Trotta, 2004.

MARK, Margaret; PEARSON, Carol S. O Herói e o Fora-da-lei: como construir marcas extraordinárias usando o poder dos arquétipos. São Paulo: Cultrix, 2001.

MAROCHI, Maria Leni Gapski. Comportamento e inovação organizacional: um estudo de caso através da tipologia de Jung. 2003. Tese (Doutorado) - Universidade Federal de Santa Catarina, Florianópolis.

PALADINI, Edson Pacheco. Gestão estratégica da qualidade: princípios, métodos e processos. São Paulo: Atlas, 2008.

RAMOS, Luís Marcelo Alves. Apontamentos sobre a psicologia analítica de Carla Gustav Jung. ETD Educação Temática Digital, Campinas, v. 4, n. 1, p. 110-144, dez. 2002.

SEVERINO, Antônio Joaquim. Metodologia do trabalho científico. 23. ed. São Paulo: Cortez, 2007. 